\title{
DIGITAL WORKFLOWS FOR RESTORATION AND MANAGEMENT OF THE MUSEUM AFFANDI - A CASE STUDY IN CHALLENGING CIRCUMSTANCES
}

\author{
U. Herbig ${ }^{\mathrm{a}}$, G. Styhler-Aydın ${ }^{\mathrm{a}}$, D. Grandits ${ }^{\mathrm{a}}$, L. Stampfer ${ }^{\mathrm{a}}$, U. Pont ${ }^{\mathrm{b}}$, I. Mayer $^{\mathrm{a}}$ \\ ${ }^{\text {a }}$ Institute of History of Art, Building Archaeology and Restoration, Faculty of Architecture and Planning, TU Wien, Austria \\ (herbig, gudrun.styhler, doris.grandits, lukas.stampfer, irmengard.mayer)@tuwien.ac.at \\ ${ }^{\mathrm{b}}$ Department of Building Physics and Building Ecology, Faculty of Architecture and Planning, TU Wien, Austria, \\ ulrich.pont@tuwien.ac.at
}

Commission VI, WG VI/4

KEY WORDS: Affandi Museum, Integrated Building Survey, Indoor Climate Evaluation, Restoration, BIM, Building Performance Simulation

\begin{abstract}
:
The appropriate restoration of architectural heritage needs a careful and comprehensive documentation of the existing structures, which even elaborates, if the function of the building needs special attention, like in museums.

In a collaborative project between the Universitas Gadjah Mada, Yogyakarta, Indonesia and two universities in Austria (TU Wien and the Danube University Krems) a restoration and adaptation concept of the Affandi Museum in Yogyakarta is currently in progress. It provides a perfect case study for the development of a workflow to combine data from a building survey, architectural research, indoor climate measurements and the documentation of artwork in a challenging environment, from hot and humid tropical climate to continuous threads by natural hazards like earthquakes or volcanic eruptions. The Affandi Museum houses the collection of Affandi, who is considered to be Indonesia's foremost Expressionist painter and partly designed and constructed the museum by himself. With the spirit of the artist still perceptible in the complex the Affandi Museum is an important part of the Indonesian cultural heritage. Thus its preservation takes special attention and adds to the complexity of the development of a monitoring and maintenance concept.

This paper describes the ongoing development of an approach to a workflow from the measurement and research of the objects, both architectural and artwork, to the semantically enriched BIM Model as the base for a sustainable monitoring tool for the Affandi Museum.
\end{abstract}

\section{INTRODUCTION}

Current solutions for facility management are often related to the term BIM (Building Information Modelling). However, the majority of BIM approaches focus on the building delivery process, and - in some cases - the operation of new buildings. So far the solutions to integrate documentations of existing building stock in available systems is not widely available, although they constitute the majority of objects in the built environment. In detail, there is a severe lack of interfaces between the existing documentation tools and routines for existing buildings, and important aspects of the building's behavior, namely the monitoring of physical processes within the buildings. Such processes, e.g. the temperature distribution over time, can have severe impact on buildings with special usages, such as museums.

A real building complex - the Affandi Museum in Yogyakarta, Indonesia - will be utilized as case study for development of an application that encompasses integrated documentation, fault detection, and maintenance of both the building and the artefacts exhibited within. There is a strong necessity for an integrated approach, due to the fact that the performance of the building directly influences the condition of the objects inside (e.g. via the indoor climate).

The Museum Affandi is a complex of gallery and art exhibition buildings in Yogyakarta, Indonesia. It houses the art works of Affandi, who is considered to be Indonesia's foremost Expressionist painter. Affandi considered the design of his museum to be important for his artistic expression, thus he defined the major architectural concept himself. Close to the 50 year anniversary of the Museum, the buildings show signs of decay and are in urgent need of restoration. Different influencing aspects, such as the hot and humid climate and potential natural hazards, e.g. earthquakes and volcano eruptions can be considered as risk factors for both the art in and architecture of the museum.

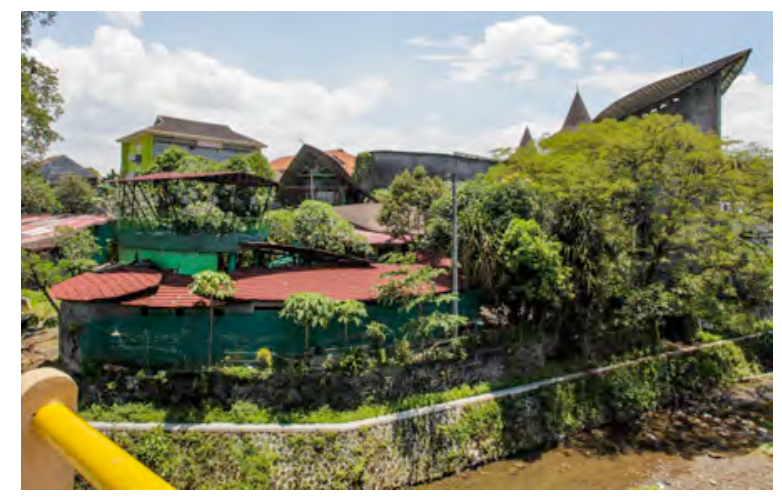

Figure 1: The Affandi Museum (U. Herbig, 2016)

As a result of the unusual design, the constructions of the complex require special maintenance.

Inspired by an idea of Mr. Affandi's daughter Kartika Affandi, two universities in Austria (TU Wien and the Danube 
University Krems) established a joint project together with the Gadjah Mada University, Yogyakarta, to develop a restoration and maintenance project for the most important artwork in the Affandi Museum ranging from the gallery buildings to paintings on canvas and paper. The project collaborators agreed upon that the required restoration should be understood as a chance to incorporate aspects of sustainability in the retrofit efforts. Furthermore, the renovation and adaptation work should be seen as an opportunity for scientific research on the buildings, their performance and their influence on the artwork.

In this paper we focus on approaches that are applied to generate a transferrable workflow from measurements and research, post processing and analysis of the data, up to the integration into a documentation tool to set up an environment for a monitoring and maintenance system.

\section{DIFFERENT DOMAINS - DIFFERENT REQUIREMENTS}

To create a solid base for the retrofit of artworks and the architecture within the complex of the Affandi Museum followed by a sustainable maintenance system, a multitude of different aspects need to be considered. Each of those aspects are important in their way and have to be considered in both, the retrofitting and the maintenance efforts.

\subsection{Climatic conditions and pollution aspects}

Yogyakarta has a hot-and-humid tropical climate and is characterized by frequent and heavy rainfall, sometimes accompanied by strong winds. Moreover, the city is permeated by heavy traffic lanes and often faces illegal garbage burning, resulting in polluted air. To offer comfortable indoor conditions, the galleries are equipped commercially available airconditioning units.

\subsection{Natural hazards}

Indonesia is located within the "pacific ring of fire", hence both volcano eruptions and earthquakes can occur frequently and without an early warning period. Ancient building traditions in Indonesia consider these conditions and are rather resistant against earthquake impacts. More recent construction habits, however, often prioritized inexpensive construction over earthquake resistance. In the course of its existence the museum was subjected to changes following natural hazards. For instance, the major earthquake of May 2006 in Indonesia (which heavily hit the island of Java, especially Yogyakarta) required reconstruction works in the first gallery that has been solely designed and constructed by Affandi. It resulted in a slightly changed appearance of the building.

\subsection{Cultural embedment}

Affandi chose Yogyakarta for the location of his museum as is the most important cultural centres of Indonesia. At the time of construction Yogyakarta was just a small town still struggling from the aftermath of the fight for independence. Still Affandi stick to his plan and contributed with the museum to establish Yogyakarta as the culture city of Indonesia. Thus the museum has a strong socio-cultural embedment as the manifesto for the existence of Indonesia's modern art.

\subsection{Usage}

The complex does not only host a permanent exhibition of Affandi's artwork, but also includes administration, visitor facilities (restaurant, coffee shop, shop, bathrooms), a lookout tower, and a workshop space, in which visitors, e.g. school classes, can attend different workshops related to contemporary art education. Moreover, there are facilities for artwork storage, artwork restoration, and residential spaces for parts of Affandi's family and museum employees.

\subsection{Building Morphology}

Designing the museum started in 1962 after Affandi's return to Yogyakarta. The realization of the complex took several decades until the current state emerged. Over the course of time several buildings were added to the complex, and different modifications were performed. Affandi developed the layout of the overall complex of the museum. His original design was implemented in his residential building and in gallery 1 and was inspired by the banana leave. As a result, the conglomerate of buildings, which is spread out over a $3500 \mathrm{~m}^{2}$ terraced plot of land features an interesting site plan, which is seen as a pleasingly harmonious overall appearance by most visitors.

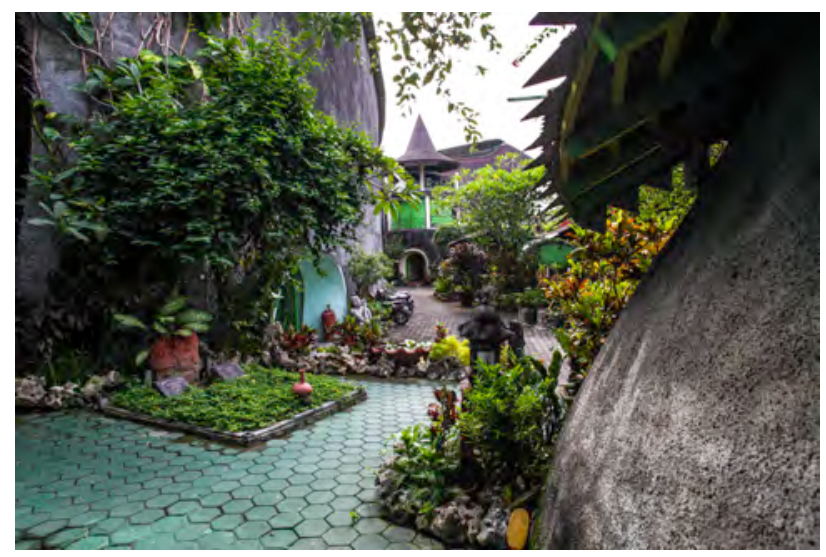

Figure 2: Affandi's grave at the Museum Affandi (U. Herbig 2016)

\subsection{Art}

Affandi's artwork is an important part of Indonesia's cultural heritage. Thus it's safeguarding needs special attention. In the frame of the project Dr Patricia Engel, (Donau University Krems), is working on the documentation and restoration concept of the art work. For the sustainable preservation first steps have been conducted parallel to the building survey and include a detailed survey of the drawings, the development of a conservation strategy for all paper based art by Affandi and introduction of the restoration measures described in the strategy to the staff of the Affandi Museum. An additional concern is the inventory of the art work that is still kept in the museum as it could be the base for an inventory of the originals created by Affandi, which becomes more and more important as the number of forgeries is increasing.

\section{SURVEY}

As the different challenges and aspects of the museum's retrofit generate a complex context, it was decided to deploy an integrative design approach. Thereby, state-of-the-art methods from the fields of building surveying, building archaeology, building performance assessment and building information modelling were utilized. The combination of these offers promising advantages regarding data acquisition, illustration and integrative evaluation of the status quo of the buildings 
(existing problems and damages), and in development of tailormade retrofit solutions.

The integrated approach for the documentation includes the measurement of the objects by hand, the preparation of a local coordinate system, a detailed to deformation survey using 3D laser scanning, as well as a comprehensive documentation by images and an accompanying research into the history of construction of the museum.

\subsection{Building survey}

Since no appropriate plan of the overall museum complex was available at the beginning of the work, the survey started with the preparation of a detailed scale sketch of the site including all single galleries and service buildings as well as the built elements in the outdoor area. The scale sketch became the basis to plan the further steps of the measurement and is therefore an important and necessary part of an efficient survey workflow on site. It was used to plan and map the positions for the survey instruments as terrestrial 3D laser scanner and total station, to prepare the local coordinate system and to exchange such information between the different survey teams. In a second step, hand measurements were conducted for selected areas of the building complex to collect structural information and details of the architecture, to identify the used construction material and to get a first overview on damages and problems of the structures. From this perspective, the direct contact and examination of structures during the preparation of scale sketches and hand measured plans provide an essential approach to historic buildings and their features.

In our project, the preparation of the scale sketch and the conduction of hand measurements were done by architecture students of the Universitas Gadjah Mada (UGM) under supervision of survey experts of TU Wien in the frame of the university cooperation mentioned above.

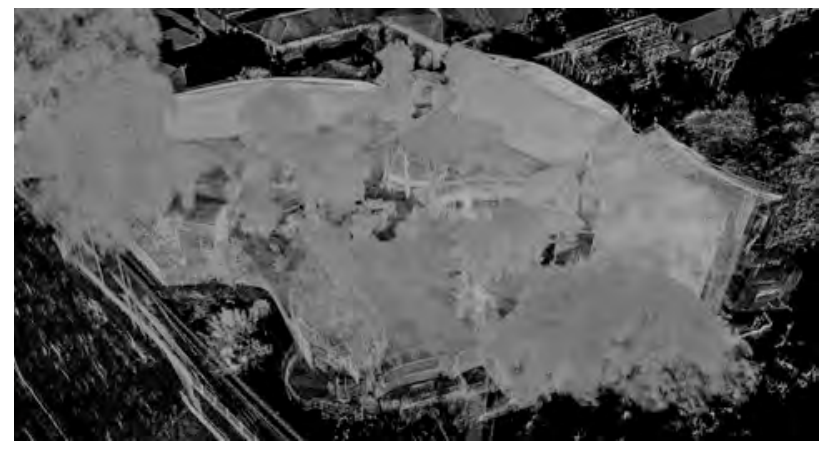

Figure 3: 3D point cloud of the Affandi Museum (D. Grandits and L. Stampfer, 2016)

The digital data acquisition for the building complex of the Museum Affandi was done by the TU Wien team with the terrestrial 3D laser scan instrument VZ-400 made by the Austrian company Riegl Laser Measurement Systems, combined with a Nikon D800 DSLR camera. In order to document the entire museum complex in its current state of preservation, all spaces interior and exterior became part of the survey area. The measured data produced a three-dimensional point cloud of the site including color information. This highly accurate geometric data set is used for all subsequent activities in the field of documentation and planning for the restoration and management of the museum, e.g. the extraction of plans, sections and elevations of the individual buildings, quantity calculations or digital modelling in further steps of the interdisciplinary analysis. In addition, the scanning process in combination with a camera also provided a near-complete photo documentation of the surveyed surfaces in their current condition.

To enable further restoration planning, firstly the digital data collected were used to elaborate necessary architectural plans. In a second step, such plans were connected in a so-called "Raumbuch" (room book) with material descriptions, mappings of damages and details of building alterations, all observed and documented during the survey on site (see 3.2 and 3.3).

\subsection{Building Archaeology}

The architectural history and development of the Affandi Museum can be traced by both details of alterations on the buildings themselves and archive documents. Beside the general development of the site during the last decades, the identified alterations of building structures are predominant related to the improvement of indoor climate and natural lighting conditions, the reaction or prevention of damages due to damp and rain water and structural improvement / repair of the buildings after the earthquake in 2006. All detected situations on the buildings were documented with detailed photos, measurements and descriptions. Additionally, a lot of valuable oral information can be still given by family members of Affandi and was documented in interviews during the survey. The different kind of data regarding the history of the Affandi museum were collected and compiled in a catalogue of features as part of the "Raumbuch" mentioned above. In further steps, the building archaeological study will result in an architectural plan set showing the building phases from the first phase of construction until today.

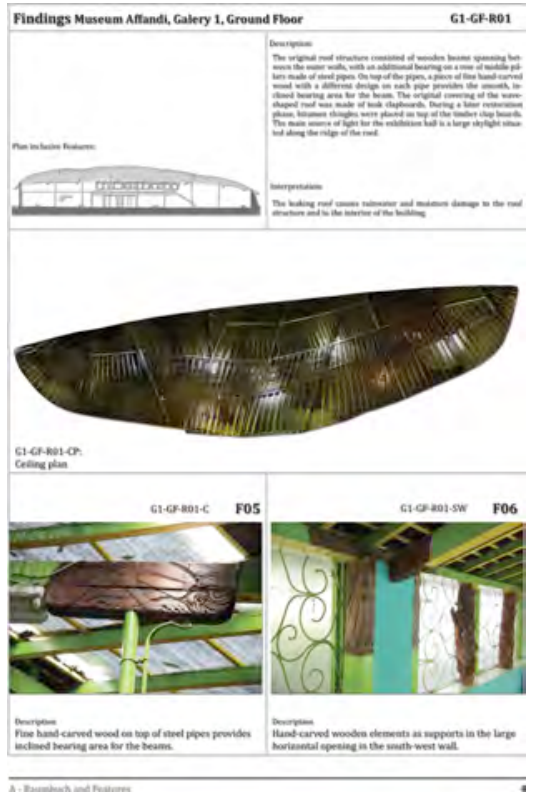

Figure 4: Room book extract of gallery 1 (G. Styhler-Aydin 2016)

\subsection{Damage Assessment}

In addition to the geometrical building survey, description of building phases and documentation of construction material, damages were systematically recorded in categories, documented by detailed photos and mapped in architectural plans as part of the "Raumbuch". In this way, the recording of 
damages is directly linked to all other information of the building survey and can be used as a starting point for the preparation and calculation of the restoration project.

\subsection{Environmental Assessment}

Subjective and objective data have been collected for the assessment of the environmental condition of the galleries of the museum. Subjective assessment was performed via a questionnaire. The questionnaires was filled out by visitors and staff and captured the perception of the indoor climate and acoustic comfort in the museum's exhibition and service spaces. Objective data was captured via sensor devices in the different galleries. This monitoring is mainly based on analogue devices. Those, being partly analogue devices, have been read out by the museum's staff in the past years, and have been used for a documentation of the indoor environment via a data log. Moreover, in a monitoring period of approximately three weeks during December 2016, indoor temperature data of higher resolution was captured via sensors with integrated data loggers.

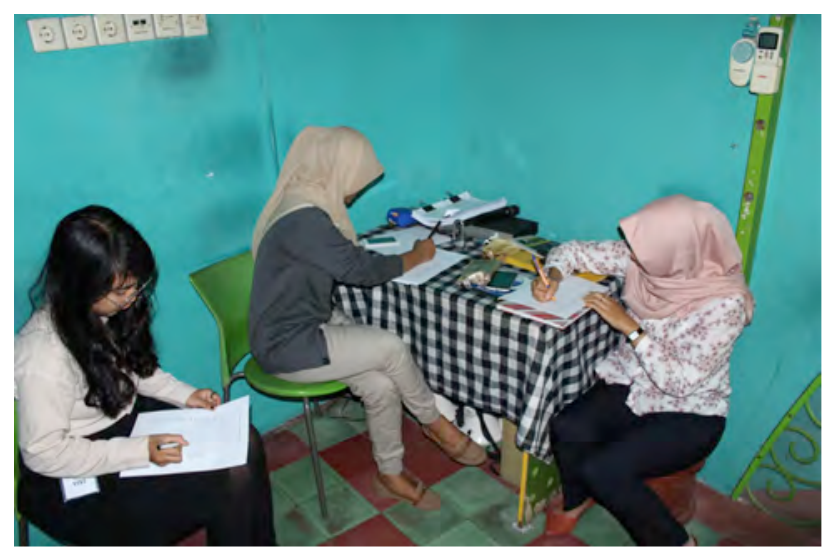

Figure 5: Museum's staff filling out the questionnaire subjective indoor comfort assessment. (U. Pont 2016)

For a continuous monitoring regarding an environmental assessment, the following data sources would be needed as integral sources of building assessment:

- Measurement of internal conditions in the most important spaces of the museum complex. The measurements currently encompass ambient temperature and relative humidity. In further measurements $\mathrm{CO} 2$-values and other parameters, such as the indoor lighting conditions and the room acoustical parameters will be captured via long-term and/or short term measurements

- Implementation of a weather station into the museum complex will enable to capture the outdoor boundary conditions, such as temperature, relative humidity, precipitation, wind speed and direction, and direct and diffuse solar radiation.

- Count and capturing of occupancy-related aspect. This encompasses the average occupancy by staff and museum's visitors and their activities, as well as the operational behaviour of building systems (doors, windows), and HVAC (in this specific case mostly air conditioning).

Moreover, the building, its constituent components and systems have been documented in the framework of the building archaeology survey. In the framework of the laser scanning, a documentation of building materials was conducted. Thereby, fundamental data of the building components, such as its physical properties was estimated, based on the findings. These values are of crucial importance regarding their impact on both the energy performance of the building and the indoor climatic conditions. To be able to assess the impact of potential changes to the building complex, currently a simulation model is constructed, to utilize numeric thermal simulation for enquiries toward energy indicators, and environmental behaviour. This state-of-the-art technology, once deployed successfully and calibrated carefully, offers an inexpensive alternative method to explore potential improvements. For instance, changes to the building's envelope can be assessed on their impact, as well as future development scenarios, such as the influence of climate change on the local microclimate can be integrated.

\subsection{Survey of the Artwork}

Dr. Patricia Engel, Danube University Krems focussed on the survey on artwork on paper during her stay in December 2016. To prepare a conservation plan for those works it is essential to investigate which paper and what kind of technique has been used and to document the condition of the objects today. Written archive material (books, diaries, correspondence, notes) as well as interviews with representatives of the family Affandi provided information not only about the technical aspects of the works, but also about their history. Furthermore conditions (e.g. lighting, vermin) affecting the objects have been documented.

In addition to that environmental measures were also part of the documentation of the state of the artwork within the Museum Affandi. According to Dr. Engel drastic changes of temperature and humidity during the day are most dangerous for the artwork on paper. Thus the use of air condition units during the day to provide a comfortable environment for visitors means a stressful climate for the artwork. The first assessments showed that a continuous monitoring of the environmental conditions could provide a chance for a faster intervention in case endangering drastic changes in the climate.

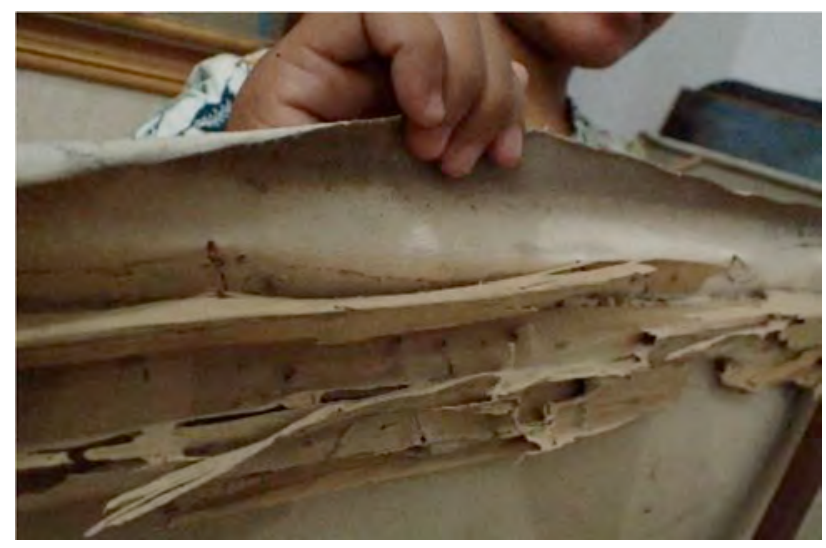

Figure 6: Termite frass in the wooden strechers (P. Engel 2016)

This documentation of a part of Affandi's oeuvre in the museum are a first step for a comprehensive inventory of his work.

\section{WORKFLOW GENERATION}

The integration of different data sources requires a shared fundamental data base: Thus, a workflow concept to obtain, store, manage, evaluate and further-process required data of the museum was outlined in a first step. This concept is illustrated in Figure 7. Following this concept, the 3D point cloud 
generated in the building survey was used for processing the plan material needed.

Based on the geodetic data acquisition, 2D and 3D building representations were generated. The $2 \mathrm{D}$ representation includes floor plans, sections, and orthophotos of the building. In this particular example the latter could not only be used for the mapping of damages, but provide also information of the artwork displayed at the time of recording. Moreover, a detailed 3D model created for the building archaeological analysis offers a representation of the buildings' complex geometries.

At the same time, general survey and photographic documentation of the complex was compiled and sorted to be related to the respective parts of the museum complex. Accordingly information, investigated via historic images, plans, and documents, as well as via interviews with Affandi's descendants and long-term museum employees has, been ordered and used for analysis of the building history of the objects of the museum complex.

As next step, a semantically enriched BIM-representation of the museum complex is currently developed. One difference between the 3D-representation and the BIM-representation is the definition of objects instead of vector information. Moreover, the semantic enrichment includes the addition of the obtained data about architectural history, as well as the integration of information pertaining to building materials and construction.

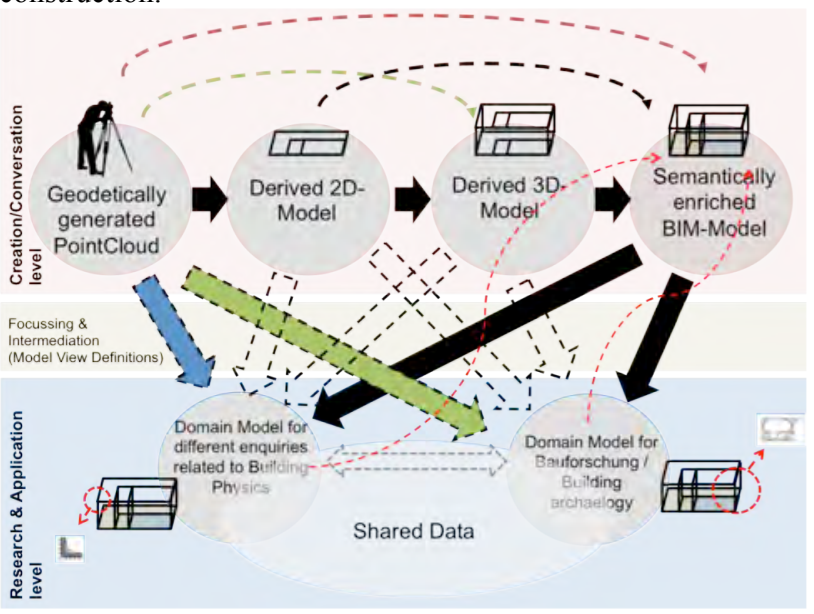

Figure 7: Data acquisition and processing concept and principle conversion to specialized domain models.

Based on these efforts, specialised domain models will be derived. These models can be used to perform specific research activities and parametric studies for the retrofit via state-of-theart computational assessment tools. For instance, indoor thermal comfort, energy consumption, and thermal performance of the buildings can be assessed. Thereby, additional data acquired in past research efforts including monitoring data of the buildings indoor conditions (temperature, relative humidity, subjective assessment of the indoor conditions of the different indoor spaces in the complex) will be utilized for calibration purposes. This step is required to ensure the quality of results obtained by simulation. Once established, the impact of different retrofit concepts can be assessed based on these domain models and different simulation tools. It seems obvious that there are overlaps in the data that is required by the different domains. Even so, different operations will be required to adapt the data for each domain model in the correct spatial and temporal resolution. To provide an example: The monitored indoor environmental data is required to develop strategies for energy savings, user comfort, and artwork conservation. However, the artwork conservation requires e.g. the information about thermal stress (e.g. fast changes of hot and chilled air) and uvradiation at the specific piece of art, while the energy performance requires long-term data of the corresponding overall gallery, and the indoor thermal comfort requires enhanced input data (operative temperature, relative humidity, air movement, clo-values, activity rate of the persons). Similar differences can be found, if looked at energy performance simulation and building archaeology applications: While both domains require precise geometry information, building performance simulation regularly requires models based on the outer perimeter, while building archaeology focuses in many cases on the inner dimensions.

In other words, the workflow not only has to integrate different data sources, but also requires methods and functionalities to provide these information bundles in specialised formats for further analysis. Given the Affandi museum's special geometry, usage patterns, and unique character, it renders a challenging, but yet exciting playground for the described novel developments.

In this context, the documentation environment docu-tools (Sustain Solutions GmbH \& Co KG 2017) will be utilized, which focuses on a easy-to-use capturing of different aspects of buildings.

\section{CONCLUSIONS}

The fieldwork in the Affandi Museum showed that an integrated system that allows the interrelated monitoring of the building, the artwork inside and the environmental conditions are urgently needed to provide a base for a sustainable, eco-friendly and economic operation and retrofit of the museum.

With the workflow developed in the framework of this project a possible approach for the processing of data from different domains to prepare it for the integration into a documentation system has been conducted. This can be considered as the first step in a novel approach toward valuable building stock utilizing digital workflows. Still there is room for improvement, especially concerning an increased automatisation in the processing of point cloud data plans and models (which are needed for different purposes) and the interlinkage between the different assessment domains. So far the proposed environment has not been used in the museum's context, but in the preparatory work for its renovation (planned for the end of 2017). This and the implementation and use of the documentation tool for the monitoring and maintenance of the museum will provide a proof of concept, if it is also applicable in the day to day work within the museum.

Furthermore, the workflow will be used in the framework of the well-established, ongoing cooperation between the UGM, TU Wien and the Affandi Museum regarding architectural heritage in Indonesia and - accordingly -will be refined and further developed. This contribution acts as a first stepping-stone and requirement outline. Moreover, it should trigger a broad discussion about our approach with domain experts from different fields. We are confident that input from designers, craftspeople, and scientists can fruitfully enrich the further development work. 


\section{ACKNOWLEDGEMENTS}

The authors are grateful to Asea UniNET for funding this first phase of the project and the company Riegl for their support. Special thanks also go to colleagues and students of the University of Gadjah Mada participating in the workshop and the staff of the Affandi Museum for their efforts. Finally, we would like to express our profound gratitude to the Affandi family, especially Kartika and Sila, for their warm welcome at the museum and their tireless support.

Furthermore we want to thank the research group of the project "Transformation of Traditional Architecture in Indonesia" for fruitful inputs.

\section{REFERENCES}

Affandi, K. (2016), Interview with Kartika Affandi conducted by Ulrike Herbig and Gudrun Styhler-Aydın, April 01. 2016 at the Affandi Museum

Engel P. (2016), Report on the ASEA Uninet Project "Development of an integrated concept for the restoration of art and architecture in Affandi Museum, Yogyakarta“ in 2016, report for ASEA Uninet

Herbig, U., Styhler-Aydin, G., Grandits, D., Stampfer, L., Pont, U. (2016): The architecture of the Affandi Museum: Approaches to a piece of Art; in: "Proceedings of the 3rd ICIAP 2016 - International Conference of Indonesian Architecture and Planning - Inclusive Space, Enriching Culture, August 11-12, 2016, Yogyakarta, Indonesia”, B. Setiawan et al. (Eds.); self published, Book of Abstracts / Proceedings (2016).

Mayer, I., Styhler-Aydın, G. (2012). 3D Laser Measurement as Part of an Integrative Building Survey for the Recording of Built Heritage; presented at: 17th International Conference on Cultural Heritage and New Technologies (November 5-7, 2012) in Vienna, Austria; ebook: http://www.chnt.at/wpcontent/uploads/eBook_CHNT17_Mayer_Styhler.pdf

Müller, V., Pont, U., Pak, H.T., Mahdavi, A. (2013). Thermal implications of radiant roof barriers: A field study in a hot and humid climate; in: "Proceedings of the 2nd Central European Symposium on Building Physics 9-11 September 2013, Vienna, Austria", A. Mahdavi, B. Martens (Eds.); ÖKK-Editions, 1 (2013), ISBN: 978-3-85437-321-6; pp. 193 - 200.

Pak, H.T., Pont, U., Müller, V., Mahdavi, A. (2013). Thermal performance of a test cell in a hot and humid climate: the impact of thermal insulation; in: "Proceedings of the 2nd Central European Symposium on Building Physics 9-11 September 2013, Vienna, Austria", A. Mahdavi, B. Martens (Eds.); ÖKKEditions, 1 (2013), ISBN: 978-3-85437-321-6; pp. 223 - 228.

Sumicahn, S. (ed.) (2007). Affandi, Vol. 1-3, Jakarta: Yayasan Bina Lestari Budaya

Sustain Solutions GmbH (2017). https://www.docu-tools.com/ (last accessed: June 2017)

Tanesia, A. (ed.) (2012). The stories of Affandi, Yogyakarta: Agung Tobing \& Museum Affandi 